\title{
Tecnored Process - High Potential in Using Different Kinds of Solid Fuels
}

\author{
José Henrique Noldin Júnior ${ }^{\mathrm{a} *}$, Marcos de Albuquerque Contrucci ${ }^{\mathrm{b} *}$, José Carlos D’Abreu ${ }^{\mathrm{c} *}$

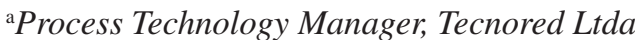 \\ ${ }^{\mathrm{b}}$ Tecnored, Tecnologia de Auto-Redução Ltda \\ ${ }^{\mathrm{c}}$ Catholic University of Rio de Janeiro, PUC-Rio
}

Received: July 19, 2004; Revised: April 25, 2005

\begin{abstract}
One important feature of the Brazilian Tecnored ironmaking process is its flexibility to use different types of solid fuels, other than metallurgical coke, as proved in the pilot plant tests by extensively using green petroleum coke, biomasses, high ash cokes, etc. Even if new solid fuels not thus far used are envisaged for a given project, thru the bench scale simulator of the process it is possible to predict the behavior of such solid fuels in the Tecnored furnace and establish the best techno-economical-environmental equation for its use. This paper discusses the key aspects involved in the use of alternative solid fuels in the Tecnored process.
\end{abstract}

Keywords: coal, solid-fuel, tecnored

\section{Introduction}

The unavoidable dependence on the use of metallurgical coke, has been appointed as the "Achilles' Heel" of the conventional blastfurnaces for the last years, earlier due to the constrains in the operation of environmentally harm coke ovens and more recently due to the worldwide shortage and skyrocketing prices of this raw material.

This new scenario of shortage and soared prices of coke has been created by the enormous steel demand on China, in turn the major exporter of coke. Despite the sharp increase in steel production in all continents, the coke exports from China have been kept at the level of 14 million tons, to attend internal demand, and therefore prices are much higher than the historical levels, as shown in Figure 1.

Since the massive installation of new coke-making capacities are unlikely to happen due to the tight environmental regulations and the high investment and construction time required, the development of new "coke-less" ironmaking technologies, seems to be crucial for the survival and growing of the steel industry in the coming years, specially for places short in metallurgical coal availability.

This paper discusses the flexibility of the Tecnored process as far as the use of alternative fuels to coke, is concerned.

\section{Solid Fuels in Ironmaking}

\subsection{Use of coke in blast-furnaces}

Further in this work, the ability of the Tecnored process to dismiss the use of coke will be explained, but first is very important to understand why coke is so important in the conventional route.

Hot metal production via conventional blast furnace is closely linked with the use of coke and therefore its availability, according to the specifications, is of extreme importance. Coke plays three vital roles in blast furnace operation, namely: Physical, Thermal and Chemical $^{2}$.

- Physical: Coke, especially as the only solid material downwards the melting zone, assures the necessary permeability to the furnace gas below, above and in the cohesive zone it self. Also, the coke bed works as a kind of basis to the huge weight of the overlying burden inside the reactor, requiring a suitable mechanical strength;

- Thermal: The burning of the carbon content in the coke thru the oxygen of the hot blast provides most of the energy used in the process; and
- Chemical: Coke is the carbon bearing material which gasifies and forms the reducing gas $\mathrm{CO}$, needed for the indirect reduction of the iron oxides in the upper part of the blast furnace. Moreover, coke is responsible for the direct reduction of the remaining $\mathrm{FeO}, \mathrm{SiO}, \mathrm{MnO}$, etc., and for the carburization of the molten iron.

To reduce coke consumption in blast furnaces to the lowest possible level, there is a trend to increase the injection of pulverized coal, oil or other alternative reducing agents, although there is a technical limit for this practice.

On the other hand, to fully replace the use of coke, some steel producers have looked at the direct use of mineral coals in blast furnaces, but most likely the three roles cannot be attained and the hot metal production is unfeasible through this route. Typical problems in blast furnaces using mineral coals are the formation of accretions due to an unsuitable thermal profile inside the reactor, low heat value and high reactivity of mineral coals, low mechanical strength causing powder generation, etc.

\subsection{Role of solid fuel in the tecnored process}

Contrary to the conventional blast furnaces, the Tecnored technology has been conceived and developed to be a "coke-less" ironmaking process, thus avoiding the investment and operation of environmentally harm coke ovens besides significantly reducing green house gases emissions (GGE) in the production of hot metal, especially if compared to the blast furnace route.

The process uses two different inputs of carbon units: the reductant and the solid fuel, optimizing the flexibility of the process. The reducing agent, normally coal fines, but virtually fines of any type of carbon enriched material can be used, is added in the mixture which will form the self-reducing agglomerates (pellets or briquettes). The quantity of coal fines required is established by a $\mathrm{C} / \mathrm{F}$ (Carbon to Iron Oxides) ratio, usually enough to achieve full reduction of the charge, by simple providing the needed heat for the process. In the self-reduction, the external $\mathrm{CO}$ does not play a significant role in the reduction process, as in the case of blast furnaces.

On the other hand, the lumpy solid fuel, also contrary to blast furnaces, is charged thru side feeders (to avoid the endothermic solution-loss reaction in the upper shaft) and is responsible to form the 
Source: Re-Net/Tecnored

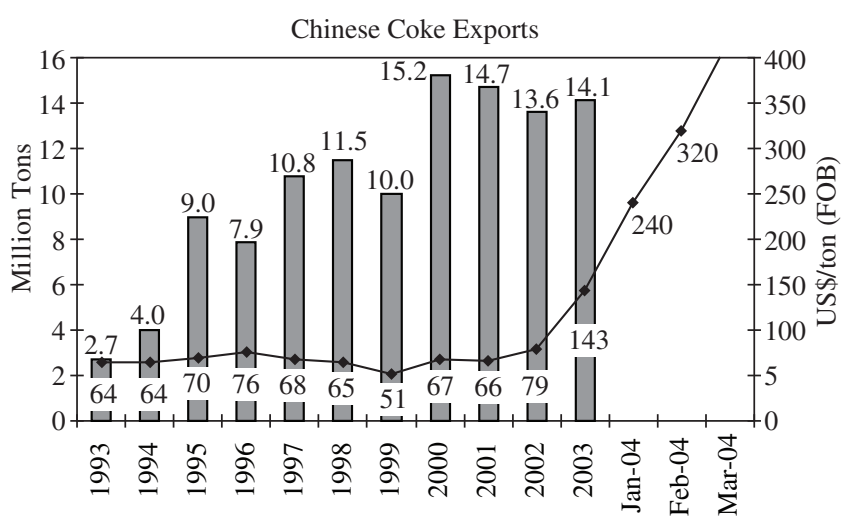

Figure 1. Chinese coke export price and volume of export ${ }^{1}$.

char bed and to provide most of the energy demanded by the process. This energy is formed by the primary blast $\left(\mathrm{C}+\mathrm{O}_{2} \rightarrow \mathrm{CO}_{2}\right)$ and by the secondary blast, where the upstream $\mathrm{CO}$, generated by the gasification of the solid fuel at the hearth, is burned $\left(\mathrm{CO}+1 / 2 \mathrm{O}_{2} \rightarrow \mathrm{CO}_{2}\right)$. Figure 2 shows a schematic cross section of the Tecnored furnace, where these two important features are highlighted.

Depending of the ultimate function the two carbon units used in the Tecnored process, present distinct specifications, not only in terms of chemical composition, but also especially in size range. The solid fuel portion requires lumpy material, typically 40 to $80 \mathrm{~mm}$, capable of handle the physical and thermal needs required form the solid fuels in the process, as shown in Figure 3.

\subsubsection{Physical and thermal role}

The lumpy coal used in the Tecnored furnace shall create the permeability in the hearth of the reactor for an even flow of the liquid and gaseous phase. Therefore, the solid fuel selected to be used in the process, in the ending-point of the side feeder, after the charification process, must to present a lumpy char, with an skeleton strong enough to support the load of the charge, besides a good reactivity to promote a suitable RAFT (raceway adiabatic flame temperature) and flame geometry, and finally able to create the desired $\mathrm{CO} / \mathrm{CO}_{2}$ ratio at the top of the char bed.

However, it is rather important to mention that the mechanical load imposed to the char bed is extremely small, due to the high volumetric productivity of the furnace, resulting on a much smaller reactor than a conventional blast furnace (Figure 4). This feature by itself is one of the main reasons that explains the ability of the furnace to dismiss the use of coke and allow the use of low-grade solid fuels.

\subsection{Solid fuels tested}

The list of solid fuels tested to be used in the Tecnored furnace is fairly extensive. Part of them has been effectively used and others have been approved after passing in the Process Simulator.

\subsubsection{Solid fuels tested in the pilot-plant}

The pilot plant development of the Tecnored process has been made in different phases, using different concepts and sizes of reactors (circular in the first phases and a modular slice of the industrial furnace in the last phase). During this period, a broad range of raw materials have been tested as charge and as fuel, always targeting the definition of the best furnace design, operation parameters, ultimate flame engineering, raceway pattern, melting zone formation and positioning, etc, in order to maximize the industrial furnace performance.

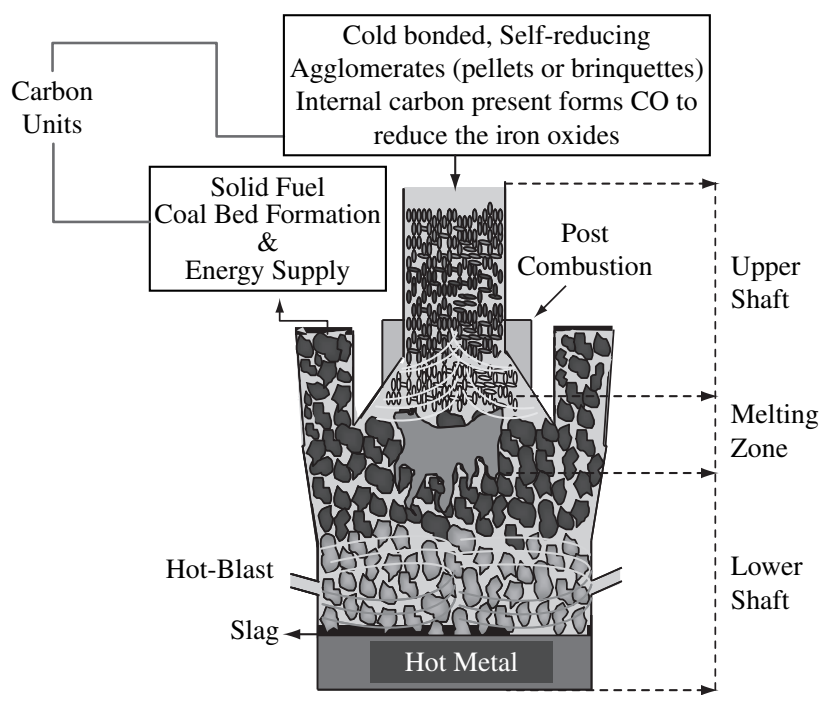

Figure 2. Cross sectional view of the Tecnored furnace.

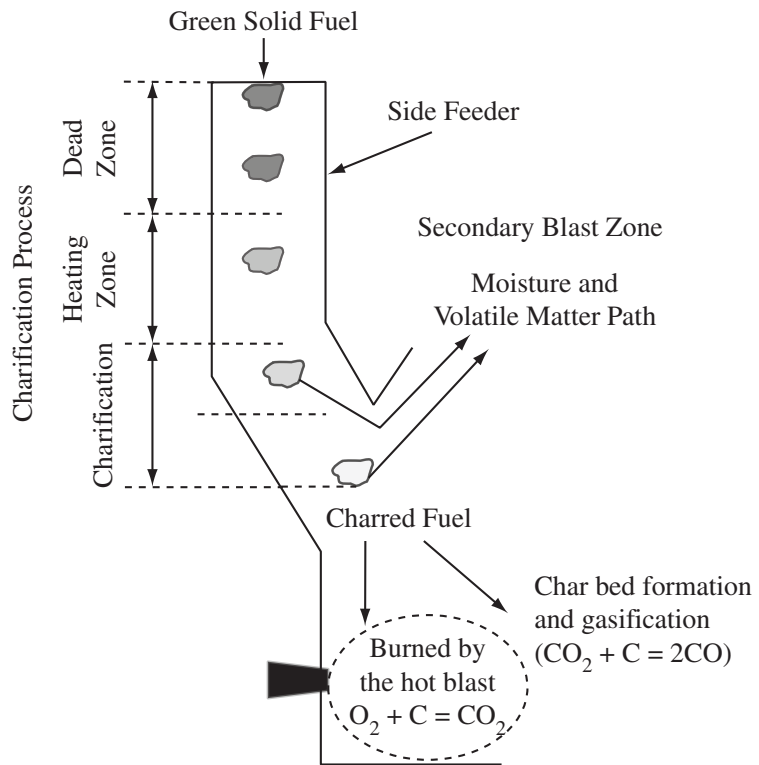

Figure 3. Charification process of the solid fuels in the Tecnored furnace.

All alternative solid fuels tested, previous to the hot operation with a ferrous burden, passed through a series of bench scale tests and process simulations in order to pre-approve its adequacy. These tests included but were not limited to, thermal shock, thermal degradation, cold test charging in the pilot furnace aiming at to evaluate the solid fuel angle of repose, distribution and segregation of different size fractions inside the reactor, etc.

The main types of solid fuels used in the pilot furnace, their typical composition and size range are shown in Table 1.

Figure 5 shows the fuel rate achieved in the hot metal production in the Tecnored pilot furnace for the different kinds of solid fuels and the specific ferrous burden used.

It is rather important to mention that the fuel rate indicated in Figure 5 is indicative only, since it varied in the trials as a function of the process parameters, ferrous burden type, Carbon/Oxide ratio in the self-reducing agglomerate, metallization degree of the DRI, 


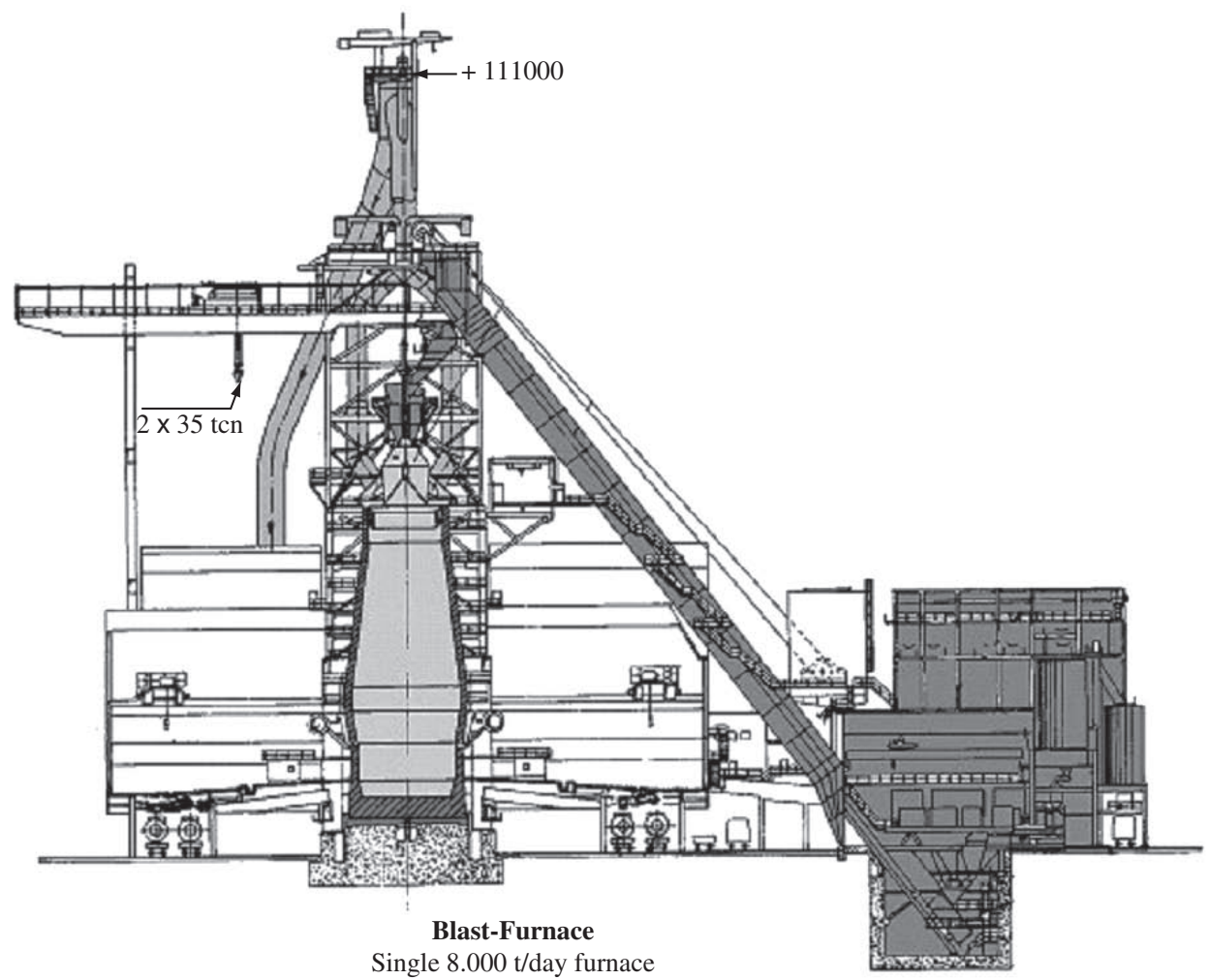

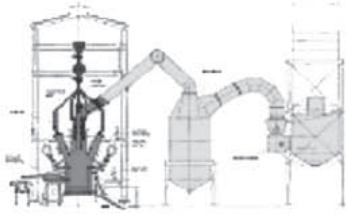

Tecnored

4 Modules of 2.000 t/day

Figure 4. Elevation of a conventional blast furnace and a Tecnored furnace.

Table 1. Main types of solid fuels tested in pilot-plant.

\begin{tabular}{lccccc}
\hline Fuel & Fixed C (\%) & $\begin{array}{c}\text { Volatile } \\
\text { Matter }(\%)\end{array}$ & Ashes $(\%)$ & S (\%) & Size Range (mm) \\
\hline Met. coke & 85.70 & 1.80 & 12.50 & $<1.00$ & $+30-60$ and $+40-80$ \\
High ash met. coke & 79.00 & 1.10 & 19.90 & $<1.00$ & $+40-100$ \\
Anthracite coal* & 50.00 & 14.00 & 36.00 & $<3.00$ & $+30-50$ \\
Pet-coke (Argent.) & 84.48 & 14.52 & 1.00 & 0.61 & $+30-60$ and + \\
Pet-coke (Brazil) & 87.00 & 12.00 & 1.00 & 0.7 & $+30-60$ and + 40 - 80 \\
Dry wood** & 47.00 & 52.20 & 0.80 & na & Varied \\
Fluff & Automotive residues (plastics $86 \%+$ sand $5 \%+$ non-ferrous metallic residues $2 \%+$ glass $7 \%)$
\end{tabular}

* According to the norm ASTM/D-388, this is a sub-bituminous type of coal, although the trade company sells as an anthracite coal.

** "Bracatinga" type wood, dried at open air yard.

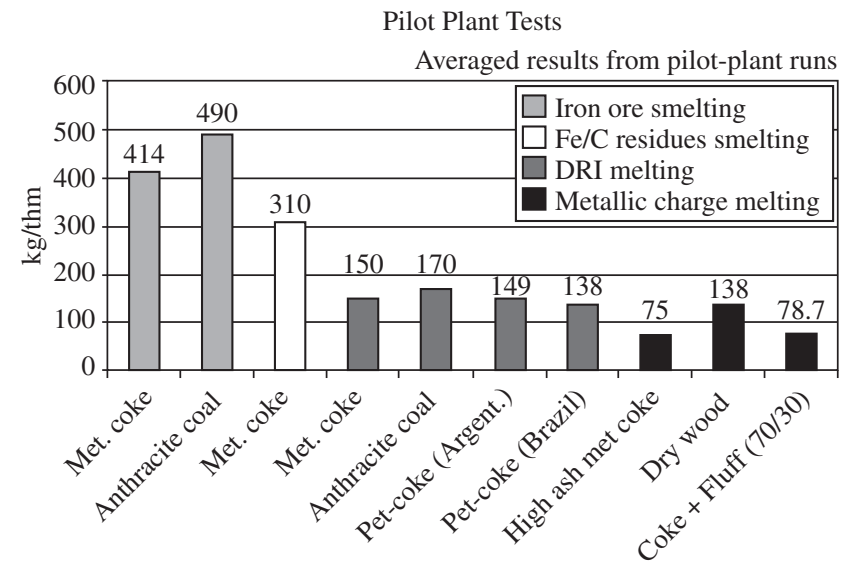

Figure 5. Fuel-rates for different ferrous burdens. size range of the iron and carbon bearing materials, moisture, etc. Therefore, for each project based on a specific set of raw materials a different fuel rate shall be envisaged.

Additionally, one should remember that the consumption norms of the industrial furnace, compared to the pilot furnace, shall be considerably lower thanks to a better furnace engineering and control, higher top pressure, lower gas and heat losses through the walls, etc.

Therefore, the lump solid-fuels to the furnace can be selected from among a number of low-cost alternatives either to be used alone or mixed, as shown in Table $2^{3}$.

Each of the fuels listed above are very attractive but for some particularities the use of anthracitic coal, green petroleum coke and biomasses are of major interests.

\subsubsection{Anthracitic coal}

The mineral coal used in the Tecnored process is different from the ones feeding coke ovens for the production of metallurgical coke. 
Table 2. Solid fuels tested and approved for adequacy in the Tecnored furnace.

\begin{tabular}{ll}
\hline Materials & Solid Fuels \\
\hline 1. Non-coking coals & $\begin{array}{l}\text { Lump anthracitic coal } \\
\text { Briquettes of coal fines }\end{array}$ \\
2. Oil refinery residues & Green Pet-coke \\
3. Low-cost cokes & Low-resistance coke (Chinese coke) \\
& High-ash semi-cokes (Indian gas plant \\
& coke) \\
& Wood chips (up to 20\% mixed with coal) \\
4. Bio-mass & Charcoal \\
& Charred wood chips \\
& Briquettes of charcoal fines \\
& Tire pieces (up to 20\% mixed with coal) \\
& Fluff (up to 20\% mixed with coal) \\
\hline
\end{tabular}

According to the ASTM designation D-3884, Tecnored can use various coals in either the Anthracitic and Bituminous group, depending mainly of the agglomerating characteristics of the coal, since the coal stream should not clog the side feeders by plastic phase formation.

For the first industrial plant in Brazil, the solid fuel selected was a South African semi-anthracitic coal, widely imported by pellet producers in Brazil, with the following proximate analysis:

- Fixed Carbon: 70 - 75\%;

- Volatile Matter: 12 - 15\%;

- Ashes: 12 - $15 \%$;

- $\mathrm{S}:<1.0 \%$;

- Moisture: $<8 \%$; and

- Size Range: 40 to $80 \mathrm{~mm}$.

\subsubsection{Green petroleum coke (pet-coke)}

Pet-Coke is a by-product in the catalytic refining process of petroleum. Pet coke has virtually no gangue or ash. Downstream hot metal De-Sulfurization process and special gas cleaning systems can be applied in case of the use of high-sulfur crude.

The use of pet-coke is always a matter of cost equation. Presently, the cost of Petrobras, extensively used pet-cokes from Betim (Minas Gerais state) and Cubatão (São Paulo state), is two to three times cheaper than coke $(\approx 80 \mathrm{US} \$ / \mathrm{t}$ of pet-coke against $250 \mathrm{US} \$ / \mathrm{t}$ of coke).

Brazilian pet-coke presents the following typical composition:

- Fixed Carbon: 85\%;

- Volatile Matter: $12 \%$;

- Ashes: $1 \%$; and

- S: $0.7 \%$.

Pet-coke is found in three main types, depending on its physical structure: Needle, Shot and Sponge. Sponge coke is more porous and contains greater surface area, is usually desired from a marketer's viewpoint $^{5}$ and is the preferred pet-coke type to be used as fuel in the Tecnored process, although the three types can be used as reductant. From those three types, needle coke is the only intentionally produced from selected feedstock and therefore accounts for less than $5 \%$ of the current production in the world.

\subsubsection{Biomasses}

The use of renewable fuels in ironmaking is being pursued worldwide targeting a green based steel production, to assure a sustainable development of the sector. In this sense the use of biomasses seems to be the best possible clean route to economically produce primary

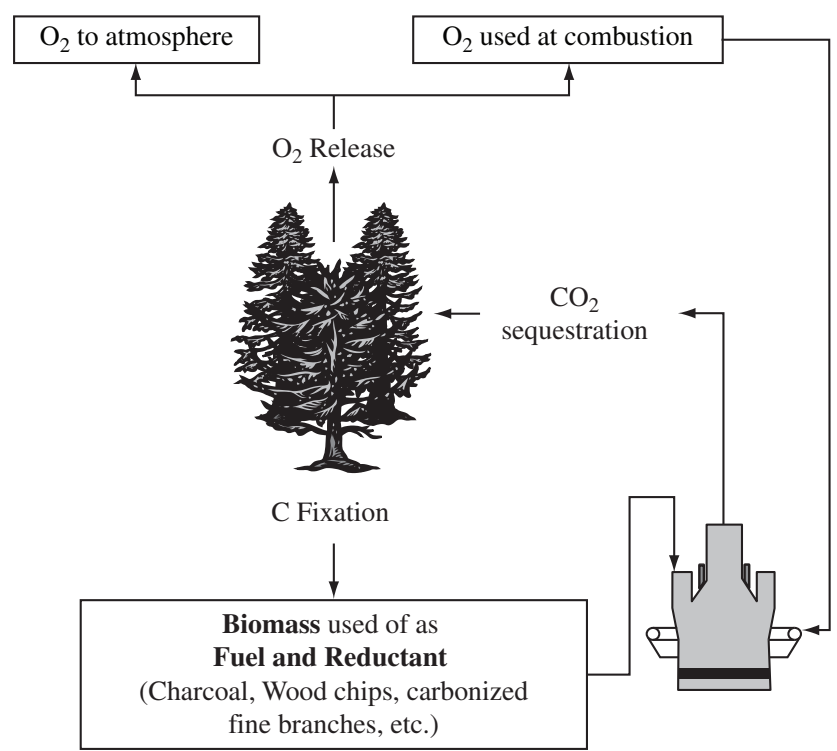

Figure 6. Cycle of $\mathrm{CO}_{2}$ sequestration.

iron, in a green house gases closed circuit where the $\mathrm{CO}_{2}$ emissions are captured and recycled in the growing process of the biomass.

The following describes this cycle, as shown in Figure 6:

- Carbon in the biomass is used as reductant and fuel in the ironmaking processes and becomes $\mathrm{CO}_{2-\mathrm{e}}$ released to the atmosphere;

- this $\mathrm{CO}_{2-\mathrm{e}}$ is captured by the replanted biomass plantations, and used for plant growing through the photosynthesis;

- the carbon is incorporated into the biomass and the oxygen is released to the atmosphere; and

- aged biomass is used and the cycle starts over again.

The carbon used in the process therefore is obtained by a nearterm closed cycle by the sequestration of the carbon from the atmosphere and not from the burning of fossil-fuel carbon. In addition, the low sulfur content in the biomass, results in very low SOx emissions ${ }^{6}$.

The Tecnored process can operate entirely with biomass, with the coarser fractions (charred or not) used as fuel and the finer fraction as reductant inside of the agglomerate. This carbon for reduction can be itself of biomass origin, such as charcoal fines or even other carbonized materials (grass, bagasse, coconut shells, corn-cobs, etc). The culture of fast growing biomasses (90 to 120 days) instead of eucalyptus (6 to 7 years) still opens the possibility for small farms participate in the iron production business, contributing for the social development of handicapped areas.

This can result in the complete use of the biomass to supply the entirely energy and reductant needs for pig iron production, assuring an environmentally friendly operation. In this approach the balance of GGE is negative, meaning that the overall sequestration of $\mathrm{CO}_{2}$ from the atmosphere for biomass growing is higher than the $\mathrm{CO}_{2}$ emissions during the production process. Furthermore, it opens the possibility to exploit the promising carbon credits marketing, estimated to range between 25.00 to $150.00 \mathrm{US} \$ /$ ton of $\mathrm{CO}^{2}$ traded, by 2015 , depending on the location.

One good example to illustrate the use of biomass in the Tecnored furnace is the use of eucalyptus trees. In this case, the trunks and the thick branches portion of the tree can be used as fuel while the fine branches and leaves can be charred, ground, and used as reductant, implying in a more cost and environment effective use of the forest assets. 
Moreover, the direct use of dry wood (3500 to $5500 \mathrm{kcal} / \mathrm{ton}$ ) instead of charcoal (5500 to $7500 \mathrm{kcal} /$ ton) as solid fuel in the process has a significant impact on the area needs for ironmaking. The productivity of a plantation of eucalyptus trees in Brazil is in the order of 14 ton/ha.yr of dry wood or 2.8 ton/ha.yr of charcoal ${ }^{7}$. To produce 1 ton of pig iron, the charcoal based mini blast furnaces consume about 0.725 ton of charcoal, so requiring $0.26 \mathrm{ha} / \mathrm{yr}$ or $2,600 \mathrm{~m}^{2} / \mathrm{yr}$ of planted area. By dismissing the use of charcoal production thru the use of wood chips as fuel (consumption $\approx 0.53$ ton/ton of hot metal) and using carbonized branches as the reductant, Tecnored can significantly increase the efficiency in the use of the planted area, fact of major importance especially for developed countries, lacking of area available for plantations.

Throughout the development of the Tecnored process, charcoal has been used extensively as reductant, in self-reducing pellets and briquettes, and has been shown to be a viable and very attractive technology. Although the use of wood as fuel has been used with success in preliminary development programs, a specific program for the development of a 100\% biomass based Tecnored reactor will be undertaken as a priority when the Tecnored industrial plant is in full production. This version of the process is expected to be a benchmarking route for iron production as well as for Carbon credits marketing and higher efficiency in the use of forest planted areas.

\section{Process Simulator for Solid Fuels}

The solid fuel nature and requirements of chemical and physical properties to be used in the Tecnored furnace shall be evaluated in relation to the solid-fuels performance in the furnace. The physical and mechanical properties for instance, depend on the degree of stabilization, grain size distribution, and cold and hot strength under different atmosphere and thermal profiles.

Tecnored devised a specific procedure to simulate the performance of such alternative solid fuels, individually or mixed, targeting to define the suitability of these materials to be used as the fuel source into the Tecnored ironmaking process, at an optimum cost equation. These simulations replicate the conditions of the process, and are required to approve the available raw materials in terms of metallurgical and mechanical properties.

\subsection{Short description of the simulation}

In order to define the suitability of the solid fuels the following standard tests are used.

- Physical characterization of the material - The size range distribution (as received), surface area, porosity, etc, of the material is determined;

- Chemical characterization - Ultimate and Proximate analysis of the materials are determined;

- Drying Test - The moisture removal rate, at a specific temperature, is measured;

- Decrepitation by Thermal Shock - An evaluation of green and charred coal degradation under thermal shock, in different testing temperature;

- Simulator Testing - Simulation of the process, under Tecnored furnace like conditions (bed interaction, temperature, control- led heating rate and gaseous atmosphere), aiming at to analyze the ultimate aspect of the samples;

- Swelling and Plasticity test - This test targets to determine the swelling and tendency to plastic phase formation, at conditions prevailing into the Tecnored Furnace;

- Coal and Charred Coal Reactivity - This test targets to determine the coal and charred coal reactivity to $\mathrm{O}_{2}$ and $\mathrm{CO}_{2}$, comparing to patterns; and

- Thermo-gravimetric tests - A set of standards for bench-scale testing to survey the behavior of solely powder coals, mixtures and agglomerates under the conditions peculiar to the Tecnored process. These tests target to define fundamental kinetic parameters.

\section{Conclusions}

From this work the following main conclusions can be drawn:

- The Tecnored process present extremely techno-economic flexibility regarding solid fuels use;

- Alternative solid fuels such as pet-coke and high ash cokes have been extensively used in the pilot-plant, after passing through the simulator;

- The process opens the possibility to use a blend of different solid fuels, in order to have a mean composition adequate to the process at the lowest cost, e.g. blend of biomasses (low S) with high sulfur pet-cokes;

- From the use of biomasses as fuel and reductant, Tecnored improves the concept of a "environmentally-friendly" operation and opens the possibility for the trading of $\mathrm{CO}_{2}$ sequestrated from the atmosphere;

- The reduction in green-house gases emissions, viz a viz the conventional ironmaking route is significant, especially considering the use of biomass; and

- The culture of fast growing biomasses (90 to 120 days) instead of eucalyptus (6 to 7 years) still opens the possibility for small farms participate in the iron production business, contributing for the social development of handicapped areas.

\section{References}

1. Jones, A. Current coke market developments. In: IPIS meeting. Dusseldorf. January 2004.

2. Lüngen HB. State of the art and future of the blast-furnace. In: IPIS meeting. Berlin. September 2001.

3. Contrucci M. Tecnored process - industrial plant in construction. In: Beyond the blast furnace conference. Atlanta, USA. June 2000.

4. Lehrman A, Blumenschein CD, Doran DJ, Stewart SE. Steel plant fuels and water requirements. In The making, shaping and treating of steel. Chapter 6, 11th Edition. AISE, USA. 1999. p 301.

5. Dymond RE. Petroleum coke - stature growing in key world markets. World coal. 1998.

6. Marcheze, ES, et al. A biomassa no processo tecnored. In International Congress on Biomass for Metal Production \& Electricity. 1st, ISS Brazilian section. Belo Horizonte. Brazil. 2001.

7. Ferreira OC. O futuro do carvão vegetal na siderurgia. $E \& E-E$ conomia e Energia. $\mathrm{n}^{\circ}$ 21. 2000. disponível em http://ecen.com. 